\title{
Long-term neuropsychological effects of ecstasy in middle-aged ecstasy/polydrug users
}

\author{
Thelma Schilt • Maarten W. J. Koeter • Johan P. Smal • \\ Mathilde N. Gouwetor • Wim van den Brink • \\ Ben Schmand
}

Received: 23 May 2009/Accepted: 23 September 2009/Published online: 13 October 2009

(C) The Author(s) 2009. This article is published with open access at Springerlink.com

\begin{abstract}
Rationale Studies reporting ecstasy-induced serotonintoxicity and (neuro)psychological dysfunctions have been conducted in young adults. Little is known about ecstasy effects later in life, when serotonin levels and cognition decrease as a consequence of normal ageing.

Objective This study aimed to assess whether harmful effects of ecstasy only add to or also interact with agerelated neuropsychological decline.

Methods Attention, verbal and visual memory, visuospatial ability, self-reported depression, sensation-seeking and impulsivity were assessed in middle-aged moderate to heavy ecstasy/polydrug users $(n=17)$ and compared with none or very mild ecstasy using polydrug users (matched for age, gender, intelligence and other drugs; $n=16)$ and a group of drug-naive controls $(n=20)$.

Results Moderate to heavy ecstasy/polydrug users performed significantly worse on a verbal memory task than none or very mild ecstasy using polydrug users and drug naives. Moderate and heavy ecstasy/polydrug users also differed significantly from drug-naives on
\end{abstract}

T. Schilt $(\bowtie) \cdot$ J. P. Smal $\cdot$ M. N. Gouwetor $\cdot$ B. Schmand Department of Psychonomics, University of Amsterdam, Roetersstraat 15, $1018 \mathrm{WB}$,

Amsterdam, The Netherlands

e-mail: t.schilt@uva.nl

M. W. J. Koeter - W. van den Brink

Department of Psychiatry, Amsterdam Institute of Addiction

Research, Academic Medical Center, University of Amsterdam,

Amsterdam, The Netherlands

B. Schmand

Department of Neurology, Academic Medical Center,

University of Amsterdam,

Amsterdam, The Netherlands measures of depression, sensation-seeking and impulsivity but not from none or very mild ecstasy-using polydrug users.

Conclusion This study in middle-aged ecstasy/polydrug users replicated findings of studies in younger ecstasy users, showing a harmful effect of ecstasy on verbal memory. There was no clear support for an interaction between harmful effects of ecstasy use and age-related memory decline or mid-life depression.

Keywords MDMA · Ecstasy · Neuropsychology · Memory · Ageing

\section{Introduction}

Between the mid 1980s and today, numerous studies have been conducted looking at the effects of the party drug ecstasy or +/-3,4-methylenedioxymethamphetamine (MDMA) on the brain and brain functions in both animals and humans. The existing literature presents converging evidence for ecstasy-induced damage to the brain serotonin system (see for reviews Reneman et al. 2006). Since serotonin is vital to mnemonic processes, cognition, mood, impulsivity and sensation seeking (Cools et al. 2008; Meneses 1999; Netter et al. 1996), many studies on the effects of ecstasy have focussed on these mental functions and behavioural characteristics. Deficits in neuropsychological functions have been reported repeatedly, with the most consistent finding being a decline in verbal memory in frequent ecstasy users (Gouzoulis-Mayfrank and Daumann 2006a; Kalechstein et al. 2007; Laws and Kokkalis 2007). Findings about the effect of ecstasy use on mood, impulsivity or sensation seeking are less conclusive. It has been argued that elevated levels of psychopathology are 
associated with polydrug use in general rather than specifically with the use of ecstasy (for reviews: Gouzoulis-Mayfrank and Daumann 2006a; GouzoulisMayfrank and Daumann 2006b; Guillot 2007).

All previous studies on the sustained (neuro)psychological effects of ecstasy have been performed in adolescents and young adults. Little is known about the effect of ecstasy on memory and mood later in life. With increasing age, serotonin levels and the number of serotonin receptors gradually reduce (Goldberg et al. 2004; McEntee and Crook 1991; Meltzer et al. 1998; Meneses 1999). In addition, the modulation by serotonin of other neurotransmitters like acetylcholine seems to decrease with age (Richter-Levin and Segal 1996). These and other biochemical changes are associated with age-related memory decline and depression (Meltzer et al. 1998). Alzheimer's disease, with memory impairment as a main symptom, is also associated with reductions in 5-HT (Lai et al. 2005) and with a cholinergic-serotonergic imbalance (GarciaAlloza et al. 2005; Meltzer et al. 1998). While depressive symptoms seem to increase with age, impulsivity and sensation seeking are thought to dwindle with age (Zuckerman 1994). Taken together, it is conceivable that frequent ecstasy use leads to memory impairments and depressive symptoms that are more severe than those observed in the normal ageing population.

However, no research about the effects of frequent ecstasy use on the ageing brain has been done yet, for the simple reason that older ecstasy users are rare. Ecstasy was introduced as a recreational drug only in the mid 1980s and was then used mainly by youngsters. In the current study we targeted middle-aged participants, who started to use ecstasy in the late 1980s/early 1990s. A complication, however, in investigating the effects of ecstasy is that most ecstasy users also use other drugs (Gouzoulis-Mayfrank and Daumann 2006b). Therefore, observed deficits could also be due to the use of psychotropic substances other than ecstasy or to a combination of other substances and ecstasy, rather than to the use of ecstasy per se. For example, various harmful effects of cocaine, amphetamine, cannabis and alcohol on neuropsychological functions have been reported in the scientific literature (e.g. Lundqvist 2005). In order to control for the use of other substances, we compared older, 'first generation' ecstasy/polydrug users with a group of older polydrug users that had very little or no experience with ecstasy and a group of older drug-naive controls. Since our previous study on the specific effects of ecstasy in a polydrug sample (Schilt et al. 2008) only revealed decreased verbal memory, whereas other cognitive domains remained spared, we now expected to find performance deficits only on verbal memory tasks in ecstasy/polydrug users compared to ecstasy-naive polydrug users. In addition, we theorised that the effect of ecstasy on the serotonin system may interact with the normal agerelated decrease in serotonin, and that this should become visible in larger effect sizes than those that have been found in younger ecstasy users.

\section{Materials and methods}

This study is a supplement to the larger Netherlands XTC Toxicity (NeXT) study, investigating long-term ecstasy neurotoxicity (de Win et al. 2005).

\section{Participants and design}

In a cross-sectional design, neuropsychological functions were compared between three groups. The first group consisted of 20 moderate to heavy ecstasy/polydrug users (minimum 240 tablets of ecstasy lifetime). Most of these ecstasy/polydrug users started to use ecstasy between 1987 and 1995. Two subjects started in 2000. Mean age of first ecstasy use was on average $32( \pm 6)$ years. The second group consisted of 18 polydrug users (minimum $50 \mathrm{~g}$ cocaine and/or amphetamine and/or more than 1,000 joints cannabis lifetime; no or very little ecstasy). Because it was very difficult to find polydrug users who had no experience with ecstasy, the use of a maximum of 15 tablets of ecstasy lifetime was permitted. The third group involved 20 drugnaive controls; social alcohol drinking (men, $<21$ drinks per week; women, $<14$ drinks per week) and tobacco use allowed. Inclusion criteria for all subjects were: age between 39 and 55 years, and Dutch as native language. Exclusion criteria for all subjects were: a major systemic, neurological or neuropsychiatric disorder known to affect cognition and/or mood (e.g. hyperthyroidism, Parkinson's disease, stroke, schizophrenia, major depression), and the use of psychotropic medications such as 5-HT reuptake inhibitors. Required abstinence from substances prior to examinations was at least 10 days for (illegal) drugs and at least 4 days for alcohol. On the day of testing, urinalysis was performed in the drug using groups: enzyme-multiplied immunoassay for amphetamines, ecstasy, opiates, cocaine, benzodiazepine, cannabis and alcohol.

A detailed drug use history questionnaire was obtained from all subjects. Lifetime use of ecstasy (tablets), alcohol (units), cannabis (number of joints), amphetamines (grams), cocaine (grams) and tobacco (cigarettes) were measured. The Dutch Adult Reading Test (DART) was administered to estimate verbal intelligence for description of the sample and comparison of the groups. The DART was chosen because it is relatively insensitive to cognitive impairment caused by neurological disorders (Schmand et al. 1991). 
The study was approved by the local ethics committee. After a complete description of the study, all subjects gave written informed consent. Subjects were paid $€ 40$ to compensate for travel expenses.

\section{Neuropsychological assessments}

The neuropsychological test battery in the current project includes tests that have shown to be sensitive to ecstasyrelated neurotoxicity and tests related to functions or brain areas that are thought to be affected by ecstasy use (e.g. prefrontal cortex, occipital cortex and hippocampus).

\section{Attention/working memory}

- Paced Auditory Serial Addition Test (PASAT; Gronwall 1977): subjects have to add numbers to a preceding number presented by a recorded male voice. Numbers are presented at a speed of $1.6 \mathrm{~s}$ per digit. The outcome parameter is the total number of correct calculations per trial (max. 60).

- Digit span (Wechsler 1981): subjects have to repeat a series of digits read aloud by the examiner; first in forward order, than in backward order. The outcome parameter is the number of correctly reproduced series of digits (max. 28).

\section{Verbal memory}

- A Dutch version of the Rey Auditory Verbal Learning Test (RAVLT; Rey 1964; Van der Elst et al. 2005): subjects have to memorise a series of 15 nouns in five learning trials. Immediate recall is tested after each trial. The outcome parameter is the sum of correctly reproduced words over five trials (max. 75). Delayed recall is measured after $20 \mathrm{~min}$. Outcome parameter is total number of correctly reproduced words (max. 15).

\section{Visual memory}

- The Memory for Designs test (Graham and Kendall 1960): the original test with 14 geometrical figures was split into two separate tests to obtain two parallel versions. The mode of administration was adapted to mimic the RAVLT. After presentation of seven figures during $5 \mathrm{~s}$ each, subjects have to draw the figures from memory. This is repeated five times. Outcome parameter is the number of correctly reproduced elements (max. three points per figure) in five learning trials (max. 105). Delayed reproduction is measured after $15 \mathrm{~min}$; outcome parameter is the number of correctly reproduced elements $(\max .21)$.

\section{Visuospatial functioning}

- A computerised and adapted version of the Judgment of Line Orientation (JoLO) (Benton et al. 1978): the JoLO requires subjects to identify which two of 11 lines presented in a semicircular array have the same orientation in a two-dimensional space as two target lines. The original JoLO was made more difficult to reduce its ceiling effect and to increase its sensitivity to brain dysfunction. The target lines in our assessments were only shown for $1 \mathrm{~s}$, directly followed by the 11 lines. The outcome parameter is the number of correctly judged pairs of lines (max. 30).

- The Mental Rotation Task (MRT; Shepard and Metzler 1971): participants are presented with 20 pairs of block designs drawn from different points of view. They have to judge whether pairs of designs are identical or different. Outcome parameter is the total number of correct answers in 6 min (max. 40).

Self-report questionnaires

\section{Depressive symptoms}

- The Beck Depression Inventory (BDI) was used to assess current depressive symptoms (Beck et al. 1961). The BDI consists of 21 items that measures characteristic attitudes of depression in the week prior to assessment; higher scores indicate more depressive symptoms. The BDI showed high reliability and validity (Beck and Steer 1984; Bouman and Kok 1987).

\section{Impulsivity}

- Impulsivity was assessed with The Dutch version of the Barratt Impulsiveness Scale (BIS-11; Patton et al. 1995). The Dutch BIS-11 contains 31 self-report items that have to be scored from 1 to 4 . The total BIS-score was used for the purpose of this study. The BIS-11 has adequate reliability.

\section{Sensation seeking}

- Sensation seeking was measured with the Spannings Behoefte Lijst (SBL; Feij et al. 1982; Feij and van Zuilen 1984), a Dutch adaptation of the American Sensation-Seeking Scale (Zuckerman and Link 1968). The SBL contains 51 sensation-seeking items and 16 filler items, on a five-point Likert scale. The total general sensation-seeking score was calculated as the sum of the four subscale scores each divided by its number of items. 
The SBL has proven to be a reliable measure for various aspects of sensation seeking in research populations (Feij et al. 1982; Feij and van Zuilen 1984).

\section{Statistical analyses}

\section{Characteristics of the sample}

Differences in age and DART-IQ between the groups were analysed with one-way analyses of variance (ANOVA), with Gabriel's post hoc procedures where appropriate. Group differences in gender were investigated using a Chi-Square test. Differences in not normally distributed drug use variables between the groups were investigated with non-parametric Kruskal-Wallis tests and Mann-Whitney post hoc analyses.

\section{Neuropsychological assessments}

Differences between the three groups in neuropsychological test scores were analysed using univariate ANCOVA, with Group (ecstasy/polydrug; polydrug; drug-naive) as between group factor. Because gender, age and DART-IQ were correlated with the cognitive outcome parameters, these variables were added as covariates.

In order to test whether the amount of ecstasy use was related to neuropsychological performance, we calculated Spearman correlations between total amount of ecstasy tablets and cognition scores in the group of ecstasy/ polydrug users.

\section{Self-report questionnaires}

Differences between the three groups in self-reported depression and impulsivity were analysed with nonparametric Kruskal-Wallis tests and Mann-Whitney post hoc analyses, because these variables were not normally distributed. Sensation seeking was analysed using univariate ANCOVA, with Group (ecstasy/polydrug/drug-naive) as between group factor.

All analyses were performed using SPSS version 16.0 (SPSS Inc., Chicago, IL, USA). Given the explicit hypotheses about the effects of heavy ecstasy use on verbal memory and depressive symptoms, scores on RAVLT and BDI were tested one sided $\left(\alpha_{1}=0.05\right)$. Because we did not have a specific hypothesis about the effects of ecstasy on other cognitive functions, self-reported impulsivity and sensation-seeking (see introduction), these significance tests were two-sided $\left(\alpha_{2}=0.05\right)$. Bonferroni corrections for multiple comparisons were applied for the number of group comparisons: ecstasy/polydrug versus polydrug and ecstasy/ polydrug versus drug naive with alpha set at $0.05 / 2=0.025$.

\section{Results}

Characteristics of the sample

Urine drug screening revealed one subject positive on benzodiazepines and four subjects positive on cannabis. These five subjects were excluded from the analyses, leaving 17 ecstasy/polydrug users, 16 polydrug users and 20 drug-naive controls for statistical analyses.

The three groups did not differ significantly in DART-IQ $\left(F_{2,50}=0.53 ; p=0.59\right)$, age $\left(F_{2,50}=0.39 ; p=0.68\right)$ and gender distribution $\left(\phi_{2}^{2}=0.76 ; p=0.68\right.$; descriptives shown in Table 1). Drug use patterns and group comparisons in drug use are presented in Table 2. As a consequence of the inclusion criteria, ecstasy use was relatively infrequent ( 10 out of 16 subjects), and significantly lower in the polydrug group (mean nine tablets lifetime) than in the ecstasy/polydrug group (mean 888 tablets lifetime). No significant differences existed between the ecstasy/polydrug group and the polydrug group in the lifetime exposure to amphetamines, cocaine, cannabis, alcohol and tobacco. The drug-naive group by definition did not use illegal drugs and used significantly less alcohol and tobacco than the ecstasy/polydrug group.

\section{Neuropsychological testing}

Descriptive data and group comparisons of neuropsychological tests are depicted in Table 3. Univariate ANCOVA with neuropsychological test scores as dependent variables, and gender, age and DART-IQ as covariates demonstrated a significant group effect on RAVLT immediate recall and RAVLT delayed recall. Post hoc analyses showed that the RAVLT immediate and delayed recall scores of the ecstasy/ polydrug group were significantly lower than those of the polydrug group and the drug-naive group. Adding scores on the BDI, BIS and SBL as covariates did not change the results.

\section{Self-report questionnaires}

Groups differed significantly on the BDI, BIS and the SBL. Post hoc analyses showed that all self-report questionnaire scores were significantly higher in the ecstasy/polydrug group compared to the drug-naives, but not compared to the polydrug group, indicating the absence of a specific effect of ecstasy use on depression, impulsivity and sensation-seeking.

Relationship between outcome parameters, amount of ecstasy use and abstinence duration

Within the group of ecstasy/polydrug users, no significant dose-response relationship was found between the cumulative number of ecstasy tablets and RAVLT immediate recall (Spearman's rho $=0.17 ; p=0.25$ ) or RAVLT delayed 
Table 1 Demographics of the three groups [mean $\pm \mathrm{SD}$ ]

\begin{tabular}{llll}
\hline & Ecstasy $(\mathrm{n}=17)$ & Polydrug $(\mathrm{n}=16)$ & Drug-naive $(\mathrm{n}=20)$ \\
\hline Males/females & $10 / 7$ & $7 / 9$ & $10 / 10$ \\
Age & $45.6 \pm 5.3$ & $45.0 \pm 4.5$ & $46.3 \pm 3.6$ \\
IQ (DART score) & $103 \pm 11$ & $107 \pm 12$ & $103 \pm 12$ \\
\hline
\end{tabular}

recall (Spearman's rho $=0.28 ; p=0.14$ ). Also no significant associations were found between verbal memory performance and abstention period (RAVLT immediate recall: Spearman's rho $=0.14 ; p=0.30$; RAVLT delayed recall: Spearman's rho $=0.24 ; p=0.17$ ).

To further explore whether ex-ecstasy users improve after quitting the use of ecstasy, we divided the group of ecstasy/ polydrug users in current ecstasy users (last use $<6$ months; $n=11$ ) and ex-ecstasy users (last use $>18$ months; $n=6$ ). Execstasy users recalled $45.5 \pm 11.3$ words on the RAVLT immediate recall and $9.8 \pm 3.2$ words on the RAVLT delayed recall, whereas current ecstasy users recalled $43.3 \pm 6.4$ and $7.7 \pm 2.4$ words on immediate and delayed recall, respectively. Univariate ANCOVA with test score as dependent variable, group (current use/ex-use) as independent variable, and age, gender, DART-IQ and number of ecstasy tablets lifetime (log transformed) as covariates, showed that the differences in test scores were not significant $\left(F_{1,11}=0.08\right.$; $p=0.78$ and $F_{1,11}=1.79 ; p=0.21$, respectively).

\section{Discussion}

Most human studies on the neuropsychological effects of ecstasy use were conducted in adolescents and young adults. The current study investigated the effects of ecstasy use on neuropsychological functions in a middle-aged sample (mean age $45.5 \pm 5.3$ ). The results showed that middle-aged moderate to heavy ecstasy polydrug users performed significantly worse on a verbal memory task compared to polydrug users who had little or no experience with ecstasy (matched for age, verbal intelligence and substance use other than ecstasy) and drug-naive controls. After correction for differences in depression, impulsivity and sensation seeking these differences remained unchanged. Middle-aged ecstasy polydrug users showed more depressive symptoms, and higher impulsivity and sensation-seeking than drug-naive controls, but they did not differ from polydrug users, who had almost no experience with ecstasy.

\section{Effects of ecstasy on verbal memory}

Our findings of a decreased verbal memory performance in older ecstasy/polydrug users are in line with many other studies reporting decreased memory functioning in young ecstasy users (for review and meta-analyses: GouzoulisMayfrank and Daumann 2006a; Kalechstein et al. 2007; Laws and Kokkalis 2007; Verbaten 2003). If the harmful effects of ecstasy increase with ageing, one would expect to find greater deficits in older ecstasy users compared to

Table 2 Comparison of drug use characteristics of the three groups [mean $\pm \mathrm{SD}$ ]

\begin{tabular}{|c|c|c|c|c|c|}
\hline & \multirow[b]{2}{*}{ Ecstasy users $(n=17)$} & \multirow[b]{2}{*}{ Polydrug users $(n=16)$} & \multirow[b]{2}{*}{ Drug-naive users $(n=20)$} & \multicolumn{2}{|c|}{$P$ (Mann-Whitney tests) } \\
\hline & & & & XTC vs. polydrug & XTC vs. drug-naive \\
\hline Ecstasy & $n=17$ & $n=10$ & & & \\
\hline Tablets lifetime & $888 \pm 678$ & $9 \pm 6$ & - & 0.000 & - \\
\hline Weeks since last use & $76 \pm 119$ & $406 \pm 212$ & - & 0.000 & - \\
\hline Amphetamine & $n=13$ & $n=10$ & & & \\
\hline Grams lifetime & $318 \pm 517$ & $287 \pm 799$ & - & ns & - \\
\hline Cocaine & $n=16$ & $n=16$ & & & \\
\hline Grams lifetime & $530 \pm 753$ & $290 \pm 525$ & - & ns & - \\
\hline Cannabis & $n=16$ & $n=15$ & & & \\
\hline Joints lifetime & $7,436 \pm 10,747$ & $9,579 \pm 9,395$ & - & ns & - \\
\hline Alcohol & $n=17$ & $n=16$ & $n=20$ & & \\
\hline Units lifetime & $31,018 \pm 32,418$ & $39,703 \pm 29,362$ & $11,190 \pm 11,128$ & ns & 0.024 \\
\hline Tobacco & $n=14$ & $n=15$ & $n=10$ & & \\
\hline Cigarettes lifetime & $96,270 \pm 62,774$ & $144,203 \pm 177,397$ & $61,056 \pm 60,853$ & ns & 0.012 \\
\hline
\end{tabular}

$n s$ non-significant 
Table 3 Comparison of cognitive task performance and psychopathology questionnaires between the three groups

\begin{tabular}{|c|c|c|c|c|c|c|c|c|}
\hline & \multicolumn{3}{|c|}{ Raw scores mean $\pm \mathrm{SD}$} & \multicolumn{3}{|c|}{$\mathrm{AN}(\mathrm{C}) \mathrm{OVA}$} & \multicolumn{2}{|c|}{ Post hoc test ( $P$ values) } \\
\hline & $\begin{array}{l}\text { Ecstasy } \\
(n=17)\end{array}$ & $\begin{array}{l}\text { Polydrug } \\
(n=16)\end{array}$ & $\begin{array}{l}\text { Drug-naive } \\
(n=20)\end{array}$ & $F$ & $\mathrm{df}$ & $P$ & $\begin{array}{l}\text { Ecstasy vs. } \\
\text { polydrug }\end{array}$ & $\begin{array}{l}\text { Ecstasy vs. } \\
\text { drug-naive }\end{array}$ \\
\hline \multicolumn{9}{|l|}{ Attention/working memory } \\
\hline Digit span (max. 28 series) ${ }^{\mathrm{a}}$ & $14.4 \pm 2.3$ & $17.3 \pm 3.3$ & $16.8 \pm 4.3$ & 3.139 & 2.47 & 0.053 & - & - \\
\hline PASAT1.6 (max. 60 hits) ${ }^{\mathrm{a}}$ & $35.8 \pm 8.7$ & $38.2 \pm 7.7$ & $41.4 \pm 10.5$ & 1.633 & 2.47 & 0.206 & - & - \\
\hline \multicolumn{9}{|l|}{ Verbal memory } \\
\hline $\begin{array}{l}\text { RAVLT immediate } \\
(\max .75 \text { words })^{\mathrm{a}}\end{array}$ & $44.1 \pm 8.2$ & $50.9 \pm 9.8$ & $52.2 \pm 5.4$ & 7.800 & 2.47 & $<0.001^{\mathrm{c}}$ & $0.024^{\mathrm{c}}, 0.020^{\mathrm{b}, \mathrm{c}}$ & $0.000^{\mathrm{c}}, 0.001^{\mathrm{b}, \mathrm{c}}$ \\
\hline $\begin{array}{l}\text { RAVLT delayed } \\
\quad(\max .15 \text { words })^{\mathrm{a}}\end{array}$ & $8.5 \pm 2.8$ & $10.9 \pm 2.8$ & $11.4 \pm 2.2$ & 7.781 & 2.47 & $<0.001^{c}$ & $0.009^{\mathrm{c}}, 0.009^{\mathrm{b}, \mathrm{c}}$ & $0.001^{\mathrm{c}}, 0.005^{\mathrm{b}, \mathrm{c}}$ \\
\hline \multicolumn{9}{|l|}{ Visual memory } \\
\hline $\begin{array}{l}\text { MfD immediate } \\
\quad(\max .105 \text { elements })^{\mathrm{a}}\end{array}$ & $71.6 \pm 17.4$ & $78.5 \pm 18.9$ & $74.6 \pm 16.2$ & 0.262 & 2.47 & 0.770 & - & - \\
\hline $\begin{array}{l}\text { MfD delayed } \\
\quad(\max .21 \text { elements })^{\mathrm{a}}\end{array}$ & $18.3 \pm 2.9$ & $19.0 \pm 3.2$ & $18.8 \pm 2.9$ & 0.186 & 2.47 & 0.831 & - & - \\
\hline \multicolumn{9}{|l|}{ Visuospatial ability } \\
\hline JOLO (max. 30 pairs) ${ }^{\mathrm{a}}$ & $20.7 \pm 3.8$ & $20.7 \pm 4.5$ & $22.7 \pm 2.9$ & 2.659 & 2.47 & 0.081 & - & - \\
\hline MRT (max. 40 hits) ${ }^{\mathrm{a}}$ & $18.5 \pm 6.5$ & $16.7 \pm 6.1$ & $20.3 \pm 4.8$ & 2.077 & 2.47 & 0.137 & - & - \\
\hline \multicolumn{9}{|c|}{ Mood/impulsivity/sensation seeking } \\
\hline Beck Depression Inventory & $6.9 \pm 5.8$ & $7.8 \pm 7.7$ & $2.7 \pm 2.1$ & 4.577 & 2.50 & $0.008^{\mathrm{c}}$ & $0.358^{\mathrm{c}}$ & $0.002^{\mathrm{c}}$ \\
\hline Barratt Impulsiveness Scale & $69.5 \pm 10.0$ & $69.4 \pm 8.1$ & $59.4 \pm 6.7$ & 9.213 & 2.50 & 0.000 & 0.961 & 0.001 \\
\hline Sensation Seeking Scale & $12.9 \pm 2.1$ & $11.9 \pm 1.9$ & $9.7 \pm 1.5$ & 15.070 & 2.50 & 0.000 & 0.168 & 0.000 \\
\hline
\end{tabular}

${ }^{\mathrm{a}}$ Corrected for age, IQ and gender

${ }^{\mathrm{b}}$ After correction for BDI, BIS and SBL

${ }^{\mathrm{c}}$ One-sided significance tests, $\boldsymbol{\alpha} \mathbf{1}=\mathbf{0 . 0 2 5}$

younger ecstasy users, leading to larger effect sizes in the current study in middle-aged subjects compared to the effect sizes in studies including younger subjects. However, this comparison of effect sizes is hampered by the fact that most studies did not succeed in matching ecstasy users and controls on drug use other than ecstasy. In the current study in middle-aged subjects, differences in verbal memory performance between ecstasy/polydrug users and polydrug users were substantial (Cohen's d between 0.75 and 0.84 ). Effect sizes of four studies in younger populations using the same verbal memory test as in our study, ranged between 0.29 and 1.48 (Verbaten 2003). Important to note is that in these studies, the amount of drug use always appeared to be lower in the control group than in the ecstasy using group (Verbaten 2003). A meta-analysis of 12 studies on the effects of ecstasy on cognition, showed an effect size of $d=$ 0.85 for verbal memory (Kalechstein et al. 2007). Again, the amount of drug use was lower in controls compared to ecstasy users. Moreover, across those samples, the amount of ecstasy use, abstention periods and the use of other drugs varied substantially. Since we have compared middle-aged abstinent ecstasy/polydrug users with controls who used similar amounts of drugs other than ecstasy, the effect size of 0.84 in our study is probably more striking. To circumvent the aforementioned disparities between studies, we compared the effect sizes of our study between ecstasy/ polydrug users and drug-naive controls with those summarised by Laws and Kokkalis (2007). Laws and Kokkalis evaluated six studies in which verbal memory performance in ecstasy users was compared with drug-naive controls and calculated an effect size of $d=1.06$ (Laws and Kokkalis 2007). In our study with middle-aged participants, the effect size was only slightly larger ( $d=1.14$ with Hedges' $d$ correction for small sample sizes; Hedges and Olkin 1985). Altogether, it seems too early to conclude that the harmful effect of ecstasy on verbal memory increases with age. The current study and the comparison with other studies in youngsters suggest that the effects of ecstasy use and normal ageing on memory are additive rather than multiplicative. It is conceivable that the subjects in the current study (39-55 years) were not old enough to allow the detection of an age by ecstasy (multiplicative) interaction. Something similar has been asserted for chronic alcoholism (Munro et al. 2000). Therefore, follow-up of the current study sample may provide better information about potential age by ecstasy interactions. 
Dose-response relationship

We failed to find a relationship between verbal memory performance and lifetime amount of ecstasy tablets. This is at odds with some other studies, including our own study in younger ecstasy users (Fox et al. 2001; GouzoulisMayfrank et al. 2003; Quednow et al. 2006; Schilt et al. 2008), but it is in agreement with a meta-analysis of ecstasy studies by Verbaten (2003). Perhaps it does not matter how much ecstasy is used above a certain threshold. Another explanation for the absence of a dose-response relationship might be that individuals differ in genetic vulnerability (Schilt et al. 2009), or that the study samples (including our own) have been too small to detect a dose-response relationship.

In the current study, no association was found between verbal memory performance and the duration since last ecstasy use (abstention period). Moreover, harmful effects of ecstasy on verbal memory did not differ between current ecstasy users (ecstasy use within the last 6 months) and long-term abstainers (no ecstasy use in the past 1.5 years, range $1.5-8$ years). This may indicate that verbal memory decrements related to ecstasy use are not (quickly) reversible; a finding that is in accordance with a study of Reneman c.s. that found sustained verbal memory deficits after an abstention period of 1 year (Reneman et al. 2001).

\section{Effects of ecstasy on psychopathological symptoms}

In the current study, we found elevated psychopathology scores in middle-aged ecstasy/polydrug users compared to drug-naive subjects, but not compared to polydrug users. It seems that depressive symptoms, impulsivity and sensation-seeking are related to polydrug use in general and not specifically to the use of ecstasy. This conclusion has also been proposed by others (Gouzoulis-Mayfrank and Daumann 2006a). However, it remains unclear whether psychopathology predisposes to the use of drugs, or whether psychopathology is a consequence of using drugs.

\section{Strengths and limitations}

The study has both strengths and limitations. The most important strengths of the study are the good match between the groups of heavy ecstasy/polydrug users and the group of polydrug users, and the broad range of neuropsychological and self-report measures that was available for all subjects. We are also well aware of the limitations of the current study. First of all, inherent to the cross-sectional design, pre-morbid differences cannot be excluded. Second, the fact that some of the polydrug controls had some experience with ecstasy complicates the interpretation of the findings of this study. In our previous study in novice ecstasy users, differences in verbal memory were detected after a mean use of 3.2 tablets lifetime (Schilt et al. 2007). However, the fact that differences between the moderate/heavy and the none/mild groups of ecstasy user were found makes it very likely that ecstasy use is associated with verbal memory impairments. Of course, the existence of an undefined, not measured confounding factor cannot be ruled out. Nevertheless, we think that our groups were well matched, with the only significant difference being the amount of ecstasy use. A third limitation is that we had to rely on self-reported drug use histories. In addition, there was no certainty about the purity of ecstasy tablets that were used by the subjects in this study. In the 1980s, when most of our subjects started with ecstasy, there was no control on the content of ecstasy tablets yet. By 2004, drug monitoring services in The Netherlands showed that the percentage of ecstasy tablets containing MDMA, MDEA and/or MDA as their main component was $97.5 \%$. In 1997, however, this percentage was noticeably lower: 65.9\% (Trimbos-instituut 2005). Furthermore, although acute effects of the psychoactive substances were minimised by the requirement of a minimal abstention period of 10 days (which turned out to be at least 2 weeks for $98 \%$ of the participants), influence of recent drug use on the memory results cannot be completely excluded. Finally, we did not investigate environmental circumstances in which the drugs were used or simultaneous use of different drugs, while influence of these factors may play an important role in the neuropsychological damage of ecstasy (Parrott 2006).

\section{Conclusion}

In conclusion, this study confirms a harmful effect of ecstasy use on verbal memory in middle-aged ecstasy/ polydrug users. The study does not provide sufficient support for the hypothesis that the harmful effects of ecstasy use and the age-related memory decline and latelife depression are multiplicative. Further research, including studies with larger sample sizes, with subjects older than 60 years, and with a comparison group of younger ecstasy users, are needed to better test whether and how ecstasy use adds to the age-related decrease in serotonin levels. Both neuropsychological assessments and brain imaging techniques should be used in these studies.

Acknowledgements We thank Hylke Vervaeke for her role in the start of this study and subject recruitment, and Miriam Goudsmit for her assistance with data collection. 
Open Access This article is distributed under the terms of the Creative Commons Attribution Noncommercial License which permits any noncommercial use, distribution, and reproduction in any medium, provided the original author(s) and source are credited.

\section{References}

Beck AT, Steer RA (1984) Internal consistencies of the original and revised Beck Depression Inventory. J Clin Psychol 40:13651367

Beck AT, Ward CH, Mendelsohn M, Mock J, Erbaugh J (1961) An inventory for measuring depression. Arch Gen Psychiatry 4:561571

Benton AL, Varney NR, Hamsher KD (1978) Visuospatial judgment. A clinical test. Arch Neurol 35:364-367

Bouman TK, Kok AR (1987) Homogeneity of Beck's Depression Inventory (BDI): applying Rasch analysis in conceptual exploration. Acta Psychiatr Scand 76:568-573

Cools R, Roberts AC, Robbins TW (2008) Serotoninergic regulation of emotional and behavioural control processes. Trends Cogn Sci $12: 31-40$

de Win MM, Jager G, Vervaeke HK, Schilt T, Reneman L, Booij J, Verhulst FC, den Heeten GJ, Ramsey NF, Korf DJ, van den Brink W (2005) The Netherlands XTC Toxicity (NeXT) study: objectives and methods of a study investigating causality, course, and clinical relevance. Int J Methods Psychiatr Res 14:167-185

Feij JA, van Zuilen RW (1984) Handleiding bij de spanningsbehoeftelijst (SBL). Swets \& Zeitlinger, Lisse

Feij JA, van Zuilen RW, Gazendam A (1982) De ontwikkeling van een Nederlandse vragenlijst voor sensation seeking: de spanningsbehoeftelijst (SBL). Gedrag 10:364-383

Fox HC, Parrott AC, Turner JJ (2001) Ecstasy use: cognitive deficits related to dosage rather than self-reported problematic use of the drug. J Psychopharmacol 15:273-281

Garcia-Alloza M, Gil-Bea FJ, ez-Ariza M, Chen CP, Francis PT, Lasheras B, Ramirez MJ (2005) Cholinergic-serotonergic imbalance contributes to cognitive and behavioral symptoms in Alzheimer's disease. Neuropsychologia 442:442-449

Goldberg S, Smith GS, Barnes A, Ma Y, Kramer E, Robeson K, Kirshner M, Pollock BG, Eidelberg D (2004) Serotonin modulation of cerebral glucose metabolism in normal aging. Neurobiol. Aging 25:167-174

Gouzoulis-Mayfrank E, Daumann J (2006a) Neurotoxicity of methylenedioxyamphetamines (MDMA; ecstasy) in humans: how strong is the evidence for persistent brain damage? Addiction 101:348-361

Gouzoulis-Mayfrank E, Daumann J (2006b) The confounding problem of polydrug use in recreational ecstasy/MDMA users: a brief overview. J Psychopharmacol 20:188-193

Gouzoulis-Mayfrank E, Thimm B, Rezk M, Hensen G, Daumann J (2003) Memory impairment suggests hippocampal dysfunction in abstinent ecstasy users. Prog Neuropsychopharmacol Biol Psychiatry 27:819-827

Graham FK, Kendall BS (1960) Memory-for-design: revised general manual. Percept Motor Skills 11:147-188

Gronwall DM (1977) Paced auditory serial-addition task: a measure of recovery from concussion. Percept Mot Skills 44:367-373

Guillot C (2007) Is recreational ecstasy (MDMA) use associated with higher levels of depressive symptoms? J Psychoactive Drugs 39:31-39

Hedges LV, Olkin I (1985) Statistical methods for meta-analysis. Academic, Orlando
Kalechstein AD, De La GR, Mahoney JJ III, Fantegrossi WE, Newton TF (2007) MDMA use and neurocognition: a meta-analytic review. Psychopharmacology (Berl) 189:531-537

Lai MK, Tsang SW, Alder JT, Keene J, Hope T, Esiri MM, Francis PT, Chen CP (2005) Loss of serotonin 5-HT2A receptors in the postmortem temporal cortex correlates with rate of cognitive decline in Alzheimer's disease. Psychopharmacology (Berl) 179:673-677

Laws KR, Kokkalis J (2007) Ecstasy (MDMA) and memory function: a meta-analytic update. Hum Psychopharmacol 22:381-388

Lundqvist $T$ (2005) Cognitive consequences of cannabis use: comparison with abuse of stimulants and heroin with regard to attention, memory and executive functions. Pharmacology Biochemistry and Behavior 81:319-330

McEntee WJ, Crook TH (1991) Serotonin, memory, and the aging brain. Psychopharmacology (Berl) 103:143-149

Meltzer CC, Smith G, DeKosky ST, Pollock BG, Mathis CA, Moore RY, Kupfer DJ, Reynolds CF III (1998) Serotonin in aging, latelife depression, and Alzheimer's disease: the emerging role of functional imaging. Neuropsychopharmacology 18:407-430

Meneses A (1999) 5-HT system and cognition. Neurosci Biobehav Rev 23:1111-1125

Munro CA, Saxton J, Butters MA (2000) The neuropsychological consequences of abstinence among older alcoholics: a crosssectional study. Alcohol Clin Exp Res 24:1510-1516

Netter P, Hennig J, Roed IS (1996) Serotonin and dopamine as mediators of sensation seeking behavior. Neuropsychobiology 34:155-165

Parrott AC (2006) MDMA in humans: factors which affect the neuropsychobiological profiles of recreational ecstasy users, the integrative role of bioenergetic stress. J Psychopharmacol $20: 147-163$

Patton JH, Stanford MS, Barratt ES (1995) Factor structure of the Barratt Impulsiveness Scale. J Clin Psychol 51:768-774

Quednow BB, Jessen F, Kuhn KU, Maier W, Daum I, Wagner M (2006) Memory deficits in abstinent MDMA (ecstasy) users: neuropsychological evidence of frontal dysfunction. J Psychopharmacol 20:373-384

Reneman L, Lavalaye J, Schmand B, de Wolff FA, van den Brink W, den Heeten GJ, Booij J (2001) Cortical serotonin transporter density and verbal memory in individuals who stopped using 3,4methylenedioxymethamphetamine (MDMA or "ecstasy"): preliminary findings. Arch Gen Psychiatry 58:901-906

Reneman L, de Win MM, van den Brink W, Booij J, den Heeten GJ (2006) Neuroimaging findings with MDMA/ecstasy: technical aspects, conceptual issues and future prospects. J Psychopharmacol 20:164-175

Rey A (1964) L'examen clinique en psychologie. Presses Universitaires de France, Paris

Richter-Levin G, Segal M (1996) Serotonin, aging and cognitive functions of the hippocampus. Rev Neurosci 7:103-113

Schilt T, de Win MM, Koeter M, Jager G, Korf DJ, van den Brink W, Schmand B (2007) Cognition in novice ecstasy users with minimal exposure to other drugs: a prospective cohort study. Arch Gen Psychiatry 64:728-736

Schilt T, de Win MM, Jager G, Koeter MW, Ramsey NF, Schmand B, van den Brink W (2008) Specific effects of ecstasy and other illicit drugs on cognition in poly-substance users. Psychol Med 38:1309-1317

Schilt T, Koeter MW, de Win MM, Zinkstok JR, van Amelsvoort TA, Schmand B, den BW (2009) The effect of Ecstasy on memory is moderated by a functional polymorphism in the cathechol-Omethyltransferase (COMT) gene. Eur Neuropsychopharmacol 19:116-124 
Schmand B, Bakker D, Saan R, Louman J (1991) The Dutch Reading Test for Adults: a measure of premorbid intelligence level. Tijdschr Gerontol Geriatr 22:15-19

Shepard RN, Metzler J (1971) Mental rotation of three-dimensional objects. Science 171:701-703

Trimbos-instituut, Utrecht (2005) Nationale Drug Monitor. Jaarbericht 2005

Van der Elst W, Van Boxtel MP, Van Breukelen GJ, Jolles J (2005) Rey's verbal learning test: normative data for 1855 healthy participants aged 24-81 years and the influence of age, sex, education, and mode of presentation. J Int Neuropsychol Soc 11:290-302

Verbaten MN (2003) Specific memory deficits in ecstasy users? The results of a meta-analysis. Hum Psychopharmacol 18:281-290

Wechsler D (1981) WAIS-R manual. The Psychological Corporation, San Antonio

Zuckerman M (1994) Behavioral expressions and biosocial bases of sensation seeking. Cambridge University Press, Cambridge

Zuckerman M, Link K (1968) Construct validity for the sensationseeking scale. J Consult Clin Psychol 32:420-426 